\title{
Retraction
}

\section{Retracted: Radiation Hardness of Flash Memory Fabricated in Deep-Submicron Technology}

\author{
International Journal of Photoenergy \\ Received 27 February 2018; Accepted 27 February 2018; Published 23 May 2018 \\ Copyright (c) 2018 International Journal of Photoenergy. This is an open access article distributed under the Creative Commons \\ Attribution License, which permits unrestricted use, distribution, and reproduction in any medium, provided the original work \\ is properly cited.
}

International Journal of Photoenergy has retracted the article titled "Radiation Hardness of Flash Memory Fabricated in Deep-Submicron Technology" [1]. There was a conflict of interest between the authors and its handling Editor since they share the same affiliation and have common publications. The article was reassessed by the Editorial Board, who found that the results cannot support the conclusions. The authors state "The aim of the paper is to investigate, theoretically, experimentally, and numerically, the radiation hardness of flash memory", but this was not achieved. The theoretical analysis appears to be partial, promoting a particular technological solution. Numerical and experimental investigations intended to validate the theoretical analysis are verified on few elements. Further, the effects of ionizing radiation on stored data are well known.

\section{References}

[1] B. Cavrić, E. Dolićanin, P. Petronijević, M. Pejović, and K. Stanković, "Radiation hardness of flash memory fabricated in deep-submicron technology," International Journal of Photoenergy, vol. 2013, Article ID 158792, 7 pages, 2013. 